NBER WORKING PAPER SERIES

\title{
THE DISTORTIONARY EFFECTS OF GOVERNMENT PROCUREMENT: EVIDENCE FROM MEDICAID PRESCRIPTION DRUG PURCHASING
}

\author{
Mark Duggan \\ Fiona Scott Morton \\ Working Paper 10930 \\ http://www.nber.org/papers/w10930 \\ NATIONAL BUREAU OF ECONOMIC RESEARCH \\ 1050 Massachusetts Avenue \\ Cambridge, MA 02138 \\ November 2004
}

The authors would like to thank the Merck Corporation for generously allowing us access to IMS data. We also thank IMS for permission to use their national sales data. The first author thanks the Robert Wood Johnson and Alfred P. Sloan Foundations for support. The second author was partially supported by NSF grant 0111885. We thank Sarah Bohn, Jillian Popadak, and Sabrina Yusuf for excellent research assistance and are grateful to Alberto Abadie, Leemore Dafny, Phil Haile, Ginger Jin, Andrei Shleifer, and numerous seminar participants for helpful comments. The views expressed in the paper are those of the authors and not necessarily the views of any sponsoring organization. The views expressed herein are those of the author(s) and do not necessarily reflect the views of the National Bureau of Economic Research.

(C) 2004 by Mark Duggan and Fiona Scott Morton. All rights reserved. Short sections of text, not to exceed two paragraphs, may be quoted without explicit permission provided that full credit, including $\odot$ notice, is given to the source. 
The Distortionary Effects of Government Procurement: Evidence from Medicaid Prescription Drug Purchasing

Mark Duggan and Fiona Scott Morton

NBER Working Paper No. 10930

November 2004

JEL No. H32, H57, I11, I18, L11, L51

\section{$\underline{\text { ABSTRACT }}$}

The federal-state Medicaid program insures 43 million people for virtually all of the prescription drugs approved by the FDA. To determine the price that it will pay for a drug treatment, the government uses the average price in the private sector for that same drug. Assuming that Medicaid recipients are unresponsive to price because of the program's zero co-pay, this rule will increase prices for non-Medicaid consumers. Using drug utilization and expenditure data for the top 200 drugs in 1997 and in 2002, we investigate the relationship between the Medicaid market share (MMS) and the average price of a prescription. Our findings suggest that the Medicaid rules substantially increase equilibrium prices for non-Medicaid consumers. Specifically, a ten percentagepoint increase in the MMS is associated with a ten percent increase in the average price of a prescription. This result is robust to the inclusion of controls for a drug's therapeutic class, the existence of generic competition, the number of brand competitors, and the years since the drug entered the market. We also demonstrate that the Medicaid rules increase a firm's incentive to introduce new versions of a drug at higher prices and find empirical evidence in support of this for drugs that do not face generic competition. Taken together, our findings suggest that government procurement can have an important effect on equilibrium prices in the private sector.

Mark Duggan

University of Maryland

Department of Economics

3115C Tydings Hall

College Park, MD 20742

and NBER

duggan@econ.bsos.umd.edu
Fiona Scott Morton

Yale School of Management

135 Prospect Street

New Haven, CT 06520

and NBER

fiona.scottmorton@yale.edu 


\section{Introduction}

In 2003 the Medicaid program provided health insurance to 43 million low-income people in the U.S. and accounted for $\$ 280$ billion in federal and state government spending (CMS, 2004). This program provides coverage for most health care services and Medicaid recipients typically do not share in the cost of their medical care. A large body of previous research has investigated the effect of the Medicaid program on health insurance coverage (Cutler-Gruber, 1996), health care utilization (Currie-Grogger, 2002), health outcomes (EpsteinNewhouse, 1998), labor supply (Yelowitz, 1995), and savings (Gruber-Yelowitz, 2001). ${ }^{1}$ Taken together the findings from this research suggest that Medicaid provides valuable insurance to low-income individuals but that it introduces significant distortions in medical care purchase decisions, reduces labor supply incentives, and crowds out private insurance coverage.

One issue that has received relatively little attention in previous work is the effect of the Medicaid program on the price of health care treatments. ${ }^{2}$ This effect could be important given that Medicaid accounts for $18 \%$ of all health care expenditures in the U.S., and the prices the government pays manufacturers are a function of prices paid by non-Medicaid consumers. For example in the case of prescription drugs, Medicaid pays approximately $90 \%$ of the average price in the private market (Kaiser, 2002; NASTAD, 2002). Thus as a firm raises its price to nonMedicaid customers in the U.S. it will receive a higher price for all of Medicaid prescriptions filled. As government purchases become large, it is clear that linking prices in this way could create significant distortions in the private market.

If the absence of a co-pay makes Medicaid recipients relatively unresponsive to price, this reimbursement rule will lead firms to increase pharmaceutical prices for other consumers

\footnotetext{
${ }^{1}$ For an excellent review of this literature see Gruber (2003).

${ }^{2}$ One notable exception is Scott-Morton (1998) in which the author examines the effect of the most-favoredcustomer clause in Medicaid on price dispersion in the non-Medicaid market.
} 
above what they otherwise would be. On the other hand, certain Medicaid regulations attempt to actively steer program participants toward low-cost prescription drugs, suggesting that demand from Medicaid recipients could actually be more responsive to price than is demand from other consumers. Thus both the sign and the magnitude of Medicaid's effect on pharmaceutical prices is ultimately an empirical question.

To investigate this issue, one would ideally exploit sharp and plausibly exogenous changes in the "Medicaid market share" of one or more prescription drugs. One could then test whether prices for non-Medicaid customers were affected, holding constant other characteristics of the drug treatment that might influence equilibrium prices. Unfortunately, no such sharp changes exist, both because the number of Medicaid recipients is relatively stable over time and because the program covers all drugs immediately following their approval by the Food and Drug Administration (FDA). Even if these changes did occur, Medicaid constrains its reimbursement rate for any particular treatment to increase no more rapidly than the Consumer Price Index (CPI).

Given that we cannot exploit within-drug variation in the Medicaid market share, we therefore exploit variation across drugs. In 2002, Medicaid accounted for $18.5 \%$ of the $\$ 161$ billion in U.S. pharmaceutical spending but this varied substantially across treatments. For example, in 2002 the program accounted for less than $6 \%$ of revenues for Lipitor, the top-selling drug in the U.S. In that same year nearly $80 \%$ of U.S. revenues for the Zyprexa - the number ten seller overall - came from the Medicaid program. Our key explanatory variable is the Medicaid market share, which is defined as Medicaid revenues in year $t$ divided by total revenues in that same year. We explore the relationship of this variable with pharmaceutical prices while controlling for other observable factors that would influence this outcome variable of interest. 
Focusing first on the top 200 drugs in 1997, our findings demonstrate that pharmaceutical prices are significantly positively related with the Medicaid market share. These results are robust to the inclusion of controls for each drug's therapeutic class, the presence of generic competition, the number of non-generic competitors, and the number of years that each drug has been on the market. Our point estimate suggests that a 10-percentage point increase in the Medicaid market share is associated with a 7.5 percent increase in pharmaceutical prices for the 1997 sample. The analogous results for the top 200 drugs in 2002 are even stronger, suggesting that this same increase in the Medicaid market share is associated with a 10.0 percent increase in the average price of a prescription.

In the second main part of our paper, we explore the effect of another potentially important feature of Medicaid that limits price increases for any particular treatment to be no greater than inflation as measured by the Consumer Price Index. If the optimal price for a drug increases more rapidly than the CPI, this creates the incentive to introduce new versions of a drug with different dosage amounts or route types (e.g. capsule, liquid, tablet). Firms must weigh this incentive against the cost of filing a new drug application (NDA) with the FDA. Our results demonstrate that drugs with high Medicaid revenues introduce more new versions than do other drugs, with this effect much stronger for drugs that do not face generic competition.

Taken together, our results strongly suggest that Medicaid coverage of prescription drugs has increased the price paid by other health care consumers for these same treatments. Using our point estimates along with Medicaid shares for each of the top 200 treatments, the average price of a non-Medicaid prescription would have been $13.3 \%$ lower in 2002 in the absence of Medicaid's reimbursement rule. Our findings imply a substantially greater effect for drugs consumed differentially by Medicaid recipients, including antipsychotics and HIV 
antiretrovirals, which have Medicaid market shares of approximately $75 \%$ and $45 \%$, respectively.

It is worth noting that government involvement in this segment of the health care sector will soon increase substantially as a result of the Medicare prescription drug benefit, which will subsidize prescription drug costs for the 44 million beneficiaries of this program. Though many details of this drug coverage have not yet been set, our findings for Medicaid suggest that public health insurance can have a substantial effect on pharmaceutical prices. These unintended effects can to some extent offset the benefit to program participants and increase costs for other health care consumers as well. ${ }^{3}$ Anecdotal evidence suggests that the Medicare legislation has already increased pharmaceutical prices (Martinez, 2004).

More generally, our results suggest that governments face a tradeoff when determining how optimally to set prices for any good or service that they procure. The main benefit of using private sector prices is that governments have a difficult time "getting prices right." But a potentially important cost is the distortion of equilibrium outcomes in the private market, with this effect increasing with the government's share of the market.

The outline of the paper is as follows. Section 2 provides background on the Medicaid rules for determining pharmaceutical prices and describes the data used in our empirical analyses. In section 3 we present an illustrative model of the effect of Medicaid's reimbursement rules on a firm's profit-maximizing price for a prescription drug and on its incentive to introduce new versions of the same drug. Section 4 presents results for the effect of the Medicaid market share on average pharmaceutical prices while section 5 describes our results for the effect on the rate at which new versions of a drug are introduced. The final section concludes and discusses the implications of our results and important directions for future work.

\footnotetext{
${ }^{3}$ See Newhouse (2004) for a discussion of this legislation and the likely impact of alternative reimbursement rules.
} 


\section{Background and Data}

\section{A. Medicaid's Rules for Setting Pharmaceutical Prices}

The Medicaid program provided health insurance to nearly 43 million people during the average month in 2003 and accounted for $\$ 280$ billion in federal and state government spending in that same year. ${ }^{4}$ Medicaid recipients are a diverse group, with the program covering almost half of all births in the U.S., approximately $70 \%$ of elderly nursing home residents, and many other low-income individuals through means-tested programs such as Supplemental Security Income (SSI) and Temporary Assistance to Needy Families (TANF). The program provides insurance for hospital stays, nursing home expenses, doctor visits, prescription drugs, and virtually all other major categories of medical care. In contrast to Medicare, the program has no co-pays or deductibles and thus beneficiaries have little incentive to consider cost when choosing between alternative treatments (Duggan, 2004).

Each state administers its own Medicaid program though each is subject to a number of federal regulations. In the case of prescription drugs, the federal Center for Medicare and Medicaid Services (CMS) to a large extent sets the price that each state will pay for any of the thousands of drug treatments covered by the program at a point-in-time. There are two steps used to determine the price for a brand name (as opposed to a generic) prescription drug in the first quarter that it is available. First, the state government pays approximately $90 \%$ of the product's average wholesale price (AWP) to the pharmacy where the prescription was filled, with this scaling factor varying from a low of $86.5 \%$ in Michigan to a high of $95 \%$ in Alaska

\footnotetext{
${ }^{4}$ The number of people with one or more months of Medicaid eligibility during 2003 exceeded 50 million. The federal government covered $\$ 160$ billion of 2003 Medicaid spending with state governments covering the remaining $\$ 120$ billion.
} 
(Kaiser, 2002). ${ }^{5}$ The pharmacy also receives a small dispensing fee that is approximately $\$ 5.00$ in the typical state. Next, a rebate is calculated that is equal either to $15.1 \%$ of the average manufacturer price (AMP) or to the difference between the AMP and the lowest price given to any buyer in the U.S., whichever is greater. ${ }^{6}$ This rebate amount is multiplied by the quantity purchased by each state and paid by the manufacturer to each state program so that the effective cost of drugs to Medicaid is reduced. ${ }^{7}$

Additionally, the program specifies that after a new drug treatment enters the market its Medicaid price cannot increase faster than the rate of inflation as measured by the Consumer Price Index (CPI). ${ }^{8}$ Thus, if a firm's optimal price for a drug is increasing more rapidly than the CPI, a firm attempting to set an optimal price for both its private sales and sales to Medicaid will be constrained. However, the CPI increases apply to changes in price of the same product over time. The level at which a product is defined for purposes of Medicaid rebates is the first nine digits of the national drug code (NDC). An NDC is an eleven-digit code that defines a product perfectly: drug, form, route, and strength. The last two digits determine package size. Medicaid aggregates over package sizes to determine best price and average prices, but the remaining nine

\footnotetext{
${ }^{5}$ While defined as the "average price at which wholesalers sell a given drug to retailers" (NASTAD, 2002) the AWP is perhaps most accurately viewed as its list price and is reported by the pharmaceutical firm to CMS. Recent estimates suggest that it is nearly $20 \%$ lower than the actual average price (NHPF, 2002) though our estimates below suggest the difference is closer to $10 \%$.

6 Thus the net Medicaid price for a drug with AWP $=\$ 110$ and AMP $=\$ 90$ would be less than or equal to $\$ 85.41$ (= $(.9 * 110)-(.151 * 90))$ in a state that paid $90 \%$ of AWP. If a firm sold to a non-Medicaid customer in the U.S. at a price less than $\$ 85.41$ during that quarter then the net Medicaid price would fall below this amount. There are a number of exceptions to this general description. For example, very low prices given to teaching hospitals, clinics, or other government programs do not count as the "best price."

${ }^{7}$ Medicaid rebates in 2002 were approximately $15 \%$ of gross Medicaid spending on prescription drugs suggesting that the typical rebate is not much different from $15.1 \%$ of AMP. The definition of AMP used by CMS is "the average price at which a manufacturer sells a particular drug to purchasers, not including sales to federal purchasers or state drug assistance programs." (NASTAD, 2002). AWP is typically 10-20\% higher than AMP.

${ }^{8}$ The way this works is as follows. First a manufacturer determines if the best price or the straight $15.1 \%$ discount applies and determines the Medicaid rebate. Then it calculates whether the increase in its AMP since launch is greater than the increase in the CPI-U during that time. If so, its rebate increases by the difference between the actual AMP and the maximum allowable AMP. See http://www.cms.hhs.gov/medicaid/drugs/drug12.asp for more details. In principle a firm could to some extent offset the increase in the rebate that results from this provision by increasing AWP even more rapidly than AMP. We do not have the data to investigate this margin of response.
} 
digits define quite a detailed product. If a manufacturer alters its product to a different strength, form, or route, it will be assigned a new NDC. When a firm introduces this new product, it may be priced in any way the firm desires, and its rate of increase from that base is what is compared to CPI growth going forward.

Thus a firm that wants to increase its prices faster than the CPI can avoid the Medicaid constraint by introducing new versions of its drug. This kind of behavior was first documented in the regulation literature by Averch and Johnson (1962) and later by many others (e.g. Parker, 1999; Borrell, 1999; Olson, 1996). The distortion of activity by the regulated entity is akin to the theoretical effects found in the principal-agent literature on multitasking (Holmstrom and Milgrom (1991), where the agent's (firm's) measured action responds to incentives but is counteracted by an unmeasured action. ${ }^{9}$ Research on the Japanese market for prescription drugs documents frequent product introductions at high prices, and ascribes this behavior to a regulatory regime that allows considerable freedom to the manufacturer in setting the initial price but then imposes steep discounts after launch (Ikegami et al, 1998).

\section{B. Medicaid and IMS Utilization Data}

We merge together data from two main sources. The first source was provided by IMS Health and contains total sales of all prescription drugs nationally from 1997-2002 for each combination of manufacturer and product. The data divide drug treatments into 14 therapeutic classes with the top three including drugs used to treat mental disorders, cardiovascular illnesses, and the alimentary tract. Within each of these therapeutic classes drugs are further divided into 249 subclasses, with cholesterol reducers, antiulcerants, and antidepressants at numbers one, two, and three, respectively, in terms of total sales in 2002.

\footnotetext{
${ }^{9}$ Essentially the firm responds to the constraints/payoffs for a specific task, namely keeping price increases on existing medicines below a threshold. It uses another activity (introducing new versions of drugs) that is not specified in the regulation to mitigate the cost of the first constraint.
} 
There are 2391 different ingredient names in the data with strictly positive sales in one or more years between 1997 and 2002. An ingredient defines just one drug, though for many drugs there are multiple products in the IMS data. A new product is often introduced after the patent for a brand name drug expires and other firms start to produce generic versions of that same drug. For example soon after the patent for Prozac expired in 2001 nearly 20 firms began to produce its generic equivalent fluoxetine, which appears as a separate product from Prozac in our data. Additionally a firm may release a different product with patent protection - such as an extended release version - for its own drug. ${ }^{10}$ In the same year that Prozac's patent expired it released a new version called Prozac Weekly that patients took just once per week. This also appears as a separate product in our IMS data.

In our empirical analyses we focus on the top 200 drugs in 1997 and in 2002 in terms of total U.S. revenues in each year. We exclude over-the-counter drugs and drugs that are themselves generic, though we include brand name drugs that face generic competition. ${ }^{11}$ In measuring revenues we group together different versions of the same drug made by the innovator but do not include sales for its generic competitors. This is because we are ultimately interested in explaining the pricing and proliferation of branded drugs. Thus in the example above sales for both Prozac and Prozac Weekly would be included in U.S. revenues for Prozac but those for the generic versions of fluoxetine would not. Our 1997 sample of 200 drugs accounts for $64.1 \%$ of the $\$ 79.85$ billion $^{12}$ in total U.S. sales in the IMS data while those in our 2002 sample are responsible for $72.6 \%$ of the $\$ 160.6$ billion in total 2002 spending. We assign each drug to one

\footnotetext{
${ }^{10}$ In the IMS data changes in dosage amount or route type usually do not show up as a separate product.

${ }^{11}$ We exclude generic drugs because the Medicaid reimbursement rules are different for them. Similarly we exclude OTC drugs because most of these sales are paid for out-of-pocket regardless of an individual's health insurance.

Firms that face generic competition continue to price well above marginal cost, perhaps because of brand loyalty or inertia, and thus it makes sense to include them in our analyses of pricing.

${ }^{12}$ Dollar figures cited here and elsewhere in the paper are inflation adjusted to 2002 dollars using a 1997 CPI of 160.5 and a 2002 CPI of 179.9 .
} 
of the fourteen therapeutic categories and calculate the number of competitors for each drug as equal to the number of other ingredients within its subclass. ${ }^{13}$

Our second main source of data are the CMS State Drug Utilization files which track Medicaid spending by product code (NDC) in all 50 states and the District of Columbia in each year. In 1997 there are 26,130 nine-digit NDCs that have non-zero Medicaid utilization with total spending equal to $\$ 13.5$ billion. Thus Medicaid accounted for $16.9 \%$ of all prescription drug spending in the U.S. during that year. In 2002 the number of NDCs is 22,111 and total Medicaid prescription drug spending is $\$ 29.6$ billion. This latter figure implies that the Medicaid market share increased during our study period to $18.5 \% .^{14}$

We match the Medicaid and IMS data using drug names. ${ }^{15}$ Of the thousands of NDCs in each year, fewer than 5\% are in our top 200 drugs, though they account for $65 \%$ of Medicaid spending in 1997 and almost $70 \%$ in 2002 . The Medicaid data also includes variables that allow us to determine whether a particular version of a drug is available over-the-counter or if it is generic. As mentioned above, we drop these two types of drugs from our analysis.

Table 1 provides an example of this match for Zyprexa, the drug that accounted for more Medicaid spending than any other in 2002 and was number ten in terms of total U.S. sales. As

\footnotetext{
${ }^{13}$ In some cases a drug falls into more than one therapeutic category and/or more than one subclass. In these cases we assign the drug to the category or subclass with the highest expenditures. This is possible because the IMS data differentiates between uses of a drug and thus one can determine what fraction of revenues for the drug fall into each category or subclass.

${ }^{14}$ Note that our Medicaid expenditures do not include rebates paid to state governments, which accounted for approximately $15 \%$ of gross spending on prescription drugs in 1997 and in 2002. Despite repeated requests to CMS for this data we were unable to obtain it because they consider this data to be proprietary and do not make them available to the public. The fact that this $15 \%$ number is very close to the $15.1 \%$ of AMP described above suggests that there is not too much heterogeneity across drugs in the rebate amount as a fraction of the gross price. The absence of this data suggests that we will to some extent overstate the Medicaid market share though because our data does not include some spending by Medicaid managed care plans and other government programs that use Medicaid prices we will also understate.

${ }^{15}$ The names are rarely identical between the two files because the Medicaid names often provide details on dosage amount or route type. Thus we take care to capture all Medicaid NDC's that contain the string of each of the 200 names in our IMS data. This involved a substantial amount of hand-checking because there were some spelling errors in the Medicaid data (e.g. Prilopec instead of Prilosec).
} 
this table shows, Medicaid covered ten different versions of the drug in this year, with the first six regular tablets of different dosage amounts and the last four dissolvable tablets. ${ }^{16}$ The table also lists total Medicaid spending for each version of Zyprexa along with the number of prescriptions. Not surprisingly, the average cost per prescription is strongly positively related with the amount of olanzapine (Zyprexa's ingredient name) in each tablet. For example, the average prescription with ten-milligram tablets is 1.79 times more expensive than the average five-milligram prescription. $^{17}$

The subsequent columns list the FDA approval date for each version of Zyprexa and the date that each version entered the market. Both of these dates are included in the CMS utilization data. We define the number of NDCs for each drug in year $t$ as equaling the number with more than $0.1 \%$ of each drug's total prescriptions in that year. We define an NDC as entering between 1997 and 2002 if it had zero spending in 1997 and has more than $0.1 \%$ of the drug's prescriptions in 2002. Interestingly the four most recent versions of Zyprexa are approximately $10 \%$ more expensive than the earlier versions with the same dosage amounts.

Tables 2 and 3 provide summary statistics for our top 200 drugs in 1997 and 2002, respectively. The average drug in our 1997 sample has U.S. revenues of \$256 million and a Medicaid market share of $16.5 \%$. The corresponding figures for the 2002 sample are $\$ 583$ million and 17.7\%. For one drug in 1997 and another in 2002 Medicaid revenues exceed reported U.S. revenues and we therefore set the Medicaid share equal to $1.00{ }^{18}$ The variable Price per Prescription is equal to total Medicaid revenues divided by Medicaid prescriptions in

\footnotetext{
${ }^{16}$ In the IMS data just two Zyprexa products appear. The first, which is simply named Zyprexa, includes the first six regular tables. The second, called Zyprexa Zydis, includes the four dissolvable versions.

${ }^{17}$ The ratio for the 5 and 2.5-milligram versions is much lower. This may be because more pills are included in the typical 2.5-milligram prescription.

${ }^{18}$ The drug in 1997 is Clozaril and in 2002 is Synagis. Our results are not affected if we exclude these drugs from our subsequent empirical analyses.
} 
each year. To reduce undesirable skewness in this measure we take the log of the price per prescription with the summary statistics for this variable summarized in each table as well.

We would prefer to use the average price of a private-sector U.S. prescription but this information is unfortunately not included in our IMS data. To investigate whether our measure of price is accurate, we compared our estimates of average prescription prices for the 2002 sample with data reported for the top 50 drugs in a recent publication by the National Institute of Health Care Management (2002). In this study, the authors use data from Scott-Levin (the other main private sector source of pharmaceutical expenditure and utilization data) to calculate the average price of a prescription in the U.S. in 2001. Five of their fifty drugs are not included in our sample (because they are generic) though a regression of the log of the average price of a Medicaid prescription on the log of the Scott-Levin measure for the remaining forty-five yields a coefficient of 1.036 with a standard error of just .024. It therefore appears that our Medicaid data provides a good estimate of average pharmaceutical prices for all U.S. health care consumers, which is not surprising given that Medicaid reimbursement rates depends on these non-Medicaid prices. $^{19}$

The two tables also summarize measures of competition for each of the top 200 drugs. The variable \# of Competitors is equal to the number of non-generic drugs ${ }^{20}$ with more than $1 \%$ of revenues within the drug's IMS subclass in the relevant year. These competitors are therapeutic substitutes for the focal drug. For both samples the average of this variable is approximately 6.3. There is a substantial difference between the two samples in the fraction of drugs facing generic competition, which declines from $28 \%$ in the 1997 sample to $16.5 \%$ in the 2002 sample. This is perhaps partly because the average number of years that each drug is on

\footnotetext{
${ }^{19}$ Recall that rebates are excluded from our measure of Medicaid revenues.

${ }^{20}$ Each ingredient is counted just once and thus the number of versions of a competitor will not influence the value for this variable.
} 
the market falls from 9.1 to 8.2 and thus a smaller fraction of patents would have expired in the more recent sample. In our empirical analyses below we control for these measures of competition along with each drug's major therapeutic category when estimating the influence of the Medicaid market share on pharmaceutical prices and on the rate at which new versions of a drug are introduced.

\section{An Illustrative Model}

\section{A. Effect of Regulation on prices}

Consider a pharmaceutical firm's optimization problem after acquiring FDA approval for a drug. Assume for simplicity that the firm has a patent for the drug, that there is just one period, that there is a constant marginal cost equal to $c$, and that demand for the drug does not influence the demand for other products produced by this same firm. For simplicity we follow Scott Morton (1997) and use linear demand $Q=a-b P$. In the absence of Medicaid, the firm will choose the price of the drug to satisfy the following equation:

$$
\mathrm{P}^{*}=\frac{\mathrm{a}+\mathrm{bc}}{2 \mathrm{~b}}
$$

where $a$ represents the number of potential customers for the firm and $b$ captures the responsiveness of those consumers to price. Greater values of $b$ imply more elastic demand, which will lower the firm's profit-maximizing price.

Now consider a different drug that is otherwise equivalent, but whose customers include $m$ consumers eligible for the Medicaid program. Further suppose that these consumers would not purchase the drug at the profit-maximizing price defined above because they are low-income 
consumers. ${ }^{21}$ Also assume that once enrolled in the program, Medicaid recipients have perfectly inelastic demand for the drug. Since Medicaid recipients typically do not share in the cost of their prescription drugs, it is reasonable to assume that the actual price the firm charges the government does not affect demand in the short run. ${ }^{22}$ In the longer run, of course, the Medicaid program could decide not to purchase, or to limit purchases of, certain drugs if they become too expensive. Finally, firms are not permitted to sell only to the Medicaid segment at a price above the maximum reservation price in the non-Medicaid population; they must sell into the private market and charge a uniform price across segments. Given these three assumptions, the demand curve shifts to the right and the relationship between price and quantity on the relevant part of the demand curve is now $\mathrm{Q}=\mathrm{a}+\mathrm{m}-\mathrm{bP}$. As regulation forces the firm to sell to both the private and the Medicaid patients at the same price then the profit-maximizing price is given by:

$$
\mathrm{P}^{*}=\frac{\mathrm{a}+\mathrm{bc}+\mathrm{m}}{2 \mathrm{~b}}
$$

which is strictly increasing in the number of consumers insured by Medicaid.

Of course Medicaid recipients may not come solely from the low end of the reservation price distribution. But even if one relaxes our earlier assumption, as long as their reservation prices are not solely at the top of this distribution the optimal price will be an increasing function of the Medicaid share. For example if the m Medicaid recipients were just a random subset of potential customers for the firm, then the optimal price would be as follows:

$$
\mathrm{P}^{*}=\frac{\mathrm{a}^{2}}{2 \mathrm{~b}(\mathrm{a}-\mathrm{m})}+\frac{\mathrm{c}}{2}
$$

\footnotetext{
${ }^{21}$ This assumption is more restrictive than is necessary. For example, if the reservation price for each Medicaid recipient is strictly less than the new profit maximizing price of $(a+b c+m) / 2 b$ then the demand curve will be as described above.

${ }^{22}$ In most states enrollees pay nothing, in others a small fixed co-pay, and in others a small fee (e.g. fifty cents versus one dollar) that varies with the price of the drug (Kaiser, 2002).
} 
which is also strictly increasing in $\mathrm{m}^{23}$

\section{B. Effect of Regulation on New Drug Introductions}

As mentioned above, the Medicaid program constrains the rate at which the price of a particular treatment can increase over time to be no greater than inflation as measured by the CPI. If the profit-maximizing price for a drug is increasing more rapidly than this index then a firm could respond by introducing new versions of the same drug and price the new versions higher than the old versions. Of course, in order to place these new products on the market, the firm must receive approval from the FDA. The costs of getting approval for a new version of an existing drug are the fees paid to the FDA, the cost of the clinical trials, and delay. The firm would then optimally weigh these costs against the benefits of unconstrained pricing.

To analyze this issue more formally consider a two-period model in which a firm must decide whether to introduce a new version of a drug at the beginning of period two. Assume that total revenues for the drug in period $t$ are equal to $\mathrm{R}_{\mathrm{t}}\left(\mathrm{P}_{\mathrm{t}}\right)+\mathrm{MP}_{\mathrm{t}}$ and thus that Medicaid demand is unresponsive to price and is constant over time. Assume further that the private revenue function $\mathrm{R}_{\mathrm{t}}($.$) shifts so that the optimal unconstrained price for the drug increases from period 1$ to period 2 (otherwise the CPI constraint would not bind). And finally, for simplicity we set the discount rate, inflation as measured by the CPI, and the marginal cost of production equal to zero. The firm will then choose $\mathrm{P}_{1}$ and $\mathrm{P}_{2}$ to maximize the following profit function:

$$
\Pi=\left(\mathrm{R}_{1}\left(\mathrm{P}_{1}\right)+\mathrm{MP}_{1}\right)+\max \left(\mathrm{R}_{2}\left(\mathrm{P}_{2}\right)+\mathrm{MP}_{1}, \mathrm{R}_{2}\left(\mathrm{P}_{2}\right)+\mathrm{MP}_{2}-\mathrm{F}\right)
$$

Here the firm must determine the marginal benefit from introducing the new product at a fixed cost of F. This depends partially on the increase in profit it earns from being able to charge $\mathrm{P}_{2}$ rather than $\mathrm{P}_{1}$ to Medicaid recipients in period 2 less the approval costs $\mathrm{F}$. Begin with the naïve

\footnotetext{
${ }^{23}$ In this case, the effect of $\mathrm{m}$ on the optimal price increases with $\mathrm{m}$ - thus the first Medicaid recipient has a smaller effect on price than does the second.
} 
assumption that the price in the first period is chosen to be the same regardless of whether or not the firm chooses to introduce a new version. Then the firm will introduce a new version if:

$$
\left[\mathrm{M} *\left(\mathrm{P}_{2}^{\text {new }}-\mathrm{P}_{2}^{\text {old }}\right)\right]>\mathrm{F}+\left[\mathrm{R}_{2}\left(\mathrm{P}_{2}^{\text {old }}\right)-\mathrm{R}_{2}\left(\mathrm{P}_{2}^{\text {new }}\right)\right]
$$

In this equation, $P_{t}^{\text {new }}$ represents the optimal price in period $\mathrm{t}$ when the firm chooses to introduce a new version at the beginning of period 2 while $P_{t}^{\text {old }}$ is equal to the optimal price in period $t$ when it does not. In equation (5) it is easy to see that the increases in Medicaid revenue in period 2 must outweigh the fixed cost of introduction and the loss in private sector revenue from the higher second period price. $^{24}$

Now we move to a more general model where the firm's first period price may depend on its introduction strategy. It is straightforward to show that the firm will choose to introduce a new version if and only if:

$$
\left[\mathrm{M} *\left(\mathrm{P}_{1}^{\text {new }}+\mathrm{P}_{2}^{\text {new }}-\mathrm{P}_{1}^{\text {old }}-\mathrm{P}_{2}^{\text {old }}\right)\right]+\left[\mathrm{R}_{1}\left(\mathrm{P}_{1}^{\text {new }}\right)-\mathrm{R}_{1}\left(\mathrm{P}_{1}^{\text {old }}\right)\right]>\mathrm{F}+\left[\mathrm{R}_{2}\left(\mathrm{P}_{2}^{\text {old }}\right)-\mathrm{R}_{2}\left(\mathrm{P}_{2}^{\text {new }}\right)\right]
$$

The left-hand side of this equation captures the benefits of introducing a new version while the right-hand side equals the costs. One important benefit is the likely increase in Medicaid revenues resulting from the more flexible pricing. The other is that profits in the first period from private consumers will be higher because the firm gets closer to the value of $\mathrm{P}_{1}$ that maximizes $\mathrm{R}_{1}\left(\mathrm{P}_{1}\right)$ when it does not consider the effect of $\mathrm{P}_{1}$ on second-period Medicaid revenues. The costs include the fixed costs and the reduction in non-Medicaid revenues in period 2. When the firm introduces a new version, it will select $\mathrm{P}_{2}$ to maximize $\mathrm{R}_{2}\left(\mathrm{P}_{2}\right)+\mathrm{MP}_{2}$ rather than $\mathrm{R}_{2}\left(\mathrm{P}_{2}\right)$, implying that revenues from other consumers will decline. Whether the gain in first-period revenues from non-Medicaid consumers will more than offset the loss in second-

\footnotetext{
${ }^{24}$ Private revenues $\mathrm{R}_{2}\left(\mathrm{P}_{2}\right)$ are higher in period two if the firm does not introduce a new version because it would then choose $\mathrm{P}_{2}$ to maximize $\mathrm{R}_{2}\left(\mathrm{P}_{2}\right)$ rather than $\mathrm{MP}_{2}+\mathrm{R}_{2}\left(\mathrm{P}_{2}\right)$.
} 
period revenues from these same consumers is theoretically ambiguous. What is clear, however, is that as sales to Medicaid increase the firm will find it more attractive to introduce a new version as the benefits would be more likely to offset the fixed cost. Thus one would expect drugs with high sales to Medicaid - all else equal - to introduce more new versions in response to the program's CPI constraint. We test this along with the effect on pharmaceutical prices in our analyses below.

Before proceeding to this, three additional points are worth noting. First, given its effect on pharmaceutical prices, Medicaid coverage will increase a firm's potential profits for any particular drug and thus could lead to more innovation. ${ }^{25}$ Second, any effect of Medicaid on price may influence the behavior of individuals not eligible for Medicaid. For example by exposing them to more medical expenditure risk, individuals may optimally decide to purchase insurance for prescription drugs, which could lead to still further increases in the price of the treatment as average price elasticities decline. ${ }^{26}$ And finally, Medicaid coverage is likely to reduce allocative efficiency as some low-valuation, but inelastic, Medicaid consumers end up purchasing the drug while relatively high valuation private consumers may not. We do not explore these issues in our analyses below, though we think that each one represents an important area for future work.

\section{The Effect of Medicaid Market Share on Pharmaceutical Prices}

In this section, we investigate the effect of a drug's Medicaid market share on its average price. The model summarized in the previous section suggests that - if Medicaid recipients are relatively unresponsive to price - then the rules used by the program would increase prices for

\footnotetext{
${ }^{25}$ See Finkelstein (2004) for an investigation of the effect of vaccine coverage by the federal government.

${ }^{26}$ Alternatively individuals could try to become eligible for Medicaid given its increasing value as pharmaceutical prices rise. See Yelowitz (2002) for an estimation of the effect of state-level Medicaid generosity on SSI receipt.
} 
other health care consumers. To estimate the importance of this effect, one would ideally use sharp changes in the Medicaid market share for one or more prescription drugs. This would allow one to control for time-invariant factors that are specific to each drug, including its effectiveness, ease of use, and production costs. Unfortunately, no such changes exist because Medicaid eligibility does not change rapidly from one period to the next and because Medicaid covers a drug once it is approved by the FDA. Even if such a sharp change did exist, Medicaid constrains the rate at which the price for any treatment can increase over time.

We therefore instead exploit the considerable variation across drugs in the Medicaid market share $(M M S)$ to estimate the effect of the program on pharmaceutical prices. As our measure of $M M S$ we take the ratio of Medicaid revenues to total U.S. revenues for that same drug. ${ }^{27}$ We control for other factors that are likely to influence the profit-maximizing price for a drug, including the presence of generic competition, the number of drugs within the same subcategory that are available, and the number of years that each drug has been on the market. The existence of generics introduces substantially more, and different, competition into the market, so we include an indicator of whether or not there is generic competition (GenComp) in the specification. ${ }^{28}$ As more therapeutic substitutes (Subst) become available, the drug will face additional competition and its optimal price will decline. Additionally, newer drugs tend to be more expensive than earlier ones - because they embody more new technology - and thus it is important to control for the time (Years) that a drug has been on the market. And finally, we include indicator variables for each of the fourteen major therapeutic categories when estimating

\footnotetext{
${ }^{27}$ This differs from the fraction $(\mathrm{m} / \mathrm{a})$ of potential customers from the model above primarily because some nonMedicaid consumers will not buy the drug.

${ }^{28}$ The literature is divided on whether generic competition a) lowers the optimal price for a brand-name drug as consumers can easily substitute to a cheaper version, or b) raises the price of the brand as all elastic demanders move to the generic and the remaining customers have inelastic demand (Frank and Salkever (1997) and (1992)). We are agnostic as to which is the correct view
} 
specifications of the following type for the top 200 drugs (in terms of total U.S. revenues) in 1997 and again in 2002:

$\log \left(\right.$ Price $\left._{\mathrm{jt}}\right)=\alpha+\beta_{1} \mathrm{MMS}_{\mathrm{jt}}+\beta_{2}$ GenComp $_{\mathrm{jt}}+\beta_{3}$ Subst $_{\mathrm{jt}}+\beta_{4}$ Years $_{\mathrm{jt}}+\sum_{\mathrm{k}=1}^{14} \theta_{\mathrm{k}} * \mathrm{I}\left(\right.$ Class $\left._{\mathrm{jt}}=\mathrm{k}\right)$

In this equation, the dependent variable is equal to the log of the average price for a prescription for drug $j$ in year $t$. We transform the price variable because its distribution is quite skewed to the right as shown in Table 4. Even with this transformation the dependent variable remains skewed and thus we use an alternative measure that we describe below.

The coefficient of particular interest in equation (7) is $\beta_{1}$, which captures the relationship between the Medicaid market share and the average price of a prescription after controlling for several other factors that should exert an effect on the price. In order to assign a causal interpretation to $\beta_{1}$, two assumptions must hold. First, the Medicaid market share must be orthogonal to unobserved determinants of the price that are not adequately captured in the other explanatory variables. The fact that Medicaid recipients tend to have low incomes suggests that, in the absence of the program, the profit-maximizing price for drugs consumed differentially by them would be lower. This would bias down the OLS estimate for $\beta_{1}$. Alternatively, if drugs used mainly by Medicaid recipients deliver a greater health benefit than other drugs - and thus would have higher prices in the absence of Medicaid - then the OLS estimate would be biased upwards. One way to gauge the importance of omitted factors is to examine the sensitivity of our estimates to the inclusion of alternative control variables which we do below.

The second assumption is that the variation in drug prices does not drive the variation in Medicaid market shares. If, for example, individuals using expensive drugs qualify for Medicaid because of the high drug prices then the estimates for $\beta_{1}$ would be biased as a result of reverse 
causation. Given that less than $10 \%$ of Medicaid recipients qualify for the program because of high medical expenses ${ }^{29}$ and given that prescription drugs account for just $12 \%$ of all Medicaid spending this seems unlikely to be a significant factor.

In Table 5 we summarize the results of specifications similar to equation (7) for average prescription prices for the top 200 drugs in 1997. The first specification includes only the Medicaid market share along with 14 therapeutic category fixed effects. The point estimate of 0.716 is significant at the five percent level and suggests that a 10-percentage point increase in the Medicaid share is associated with approximately a $7.2 \%$ increase in the average price. In the second specification we include a control for the presence of generic competition. The estimate for this coefficient is negative and it is significant at the one percent level. The estimate of -.335 suggests that drugs with generic competition sell for almost 30 percent less than other drugs after controlling for the Medicaid share and each drug's therapeutic category. The inclusion of this variable has little impact on our estimate for $\beta_{1}$.

In specifications three and four we introduce controls for the number of therapeutic substitutes and the number of years that each drug has been on the market. Each coefficient is, as predicted above, negative, though only the latter variable is statistically significant.

Interestingly, the estimate for the generic competition variable declines in specification four, when we control for the number of years that each drug is on the market, presumably because older drugs are more likely to face generic competition and also tend to have lower prices. Once again the coefficient estimate for $\beta_{1}$ is virtually unchanged. The stability of the estimates for $\beta_{1}$ across specifications strongly suggests that unobservable determinants of price are not driving the estimates.

\footnotetext{
${ }^{29}$ Most instead qualify through a program such as Supplemental Security Income, Temporary Assistance to Needy Families, or because they are children with family incomes below $185 \%$ of the poverty line.
} 
Because of skewness in the distribution of the log of pharmaceutical prices, we next estimate specifications in which we use each drug's rank in the price distribution as the dependent variable. This variable is uniformly distributed from 1 to 200 with the most expensive drug having a value of 200 while the least expensive one has a value equal to one. The results using this alternative measure are summarized in the next panel of Table 5 and are qualitatively similar to those that use the log of price as the dependent variable. Once again the presence of generic competition, the number of therapeutic substitutes, and the age of the drug are all negatively related to price, and in this case all three of these estimates are statistically significant. Additionally, the estimates for the Medicaid market share are stable across specifications and suggest that drugs purchased differentially by beneficiaries of this program are significantly more expensive. The point estimate in the final specification suggests that a 10-percentage point increase in the Medicaid share is associated with an increase of 5 in that firm's position in the price distribution and this estimate is significant at the one percent level.

In Table 6 we summarize an analogous set of specifications for the top 200 drugs in 2002. The point estimates for the coefficients on the generic competition, the number of therapeutic substitutes, and the age of the drug variables are similar to those obtained using the 1997 sample though the estimated coefficients for the first two variables are not statistically significant in the final specification. Interestingly the implied effect of the Medicaid market share on the log of price and on the rank in the price distribution is substantially greater, suggesting that the effect of Medicaid may be increasing over time. And as before, the estimates for $\beta_{1}$ are quite consistent across specifications as additional explanatory variables are added.

One potentially important issue is the sensitivity of our results to the exclusion of drugs with particularly high Medicaid market shares. As recent research has shown (Duggan, 2004), 
drugs used to treat antipsychotic illness have the highest Medicaid market shares, with this program accounting for almost $80 \%$ of revenues for Zyprexa, Risperdal, Seroquel, Clozaril, and other top-selling antipsychotics. Given that these drugs are substantially more expensive than the average treatment, it is possible that their inclusion in our sample is to some extent driving our results. In a companion set of results not summarized here, we investigate the sensitivity of our estimates to excluding this set of treatments ${ }^{30}$ and find that our estimates for $\beta_{1}$ are virtually unchanged. For example the estimate of 0.746 in specification 4 of Table 5 increases to 0.752 when antipsychotic drugs are excluded while the corresponding estimate in Table 6 increases from 1.001 to 1.003 . It therefore appears that our results are not sensitive to the exclusion of the subclass of drugs with the highest Medicaid market shares. ${ }^{31}$

Our first set of results strongly suggests that the rules used by the federal government to set prices for prescription drugs have led to an increase in prices faced by other health care consumers. Given that we are exploiting variation across drugs in the Medicaid market share we cannot rule out the existence of an omitted determinant of pharmaceutical prices that is correlated with the Medicaid share and therefore could be biasing the results. But the fact that our estimates for the Medicaid share are so stable across specifications with alternative control variables suggests that our estimates are reliably capturing the causal effect of interest.

\footnotetext{
${ }^{30}$ This leads us to exclude Zyprexa, Risperdal, Seroquel (2002 only), and Clozaril (1997 only). The first three were numbers one, two, and four, respectively, in terms of total 2002 Medicaid spending. Recall that we do include fixed effects for therapeutic class, though this groups antipsychotics with other drugs used to treat mental disorders. ${ }^{31}$ An additional issue is possible mismeasurement of the Medicaid market share due to missing data on other programs that use Medicaid prices and that have zero or small co-pays. Perhaps the most important one is the AIDS Drug Assistance Program (ADAP) which accounted for more than \$250 million in HIV antiviral spending in 1997. If we adjust up our Medicaid market shares for the HIV drugs in our sample (from approximately 0.40 to 0.60 ) to account for the much higher effective shares our results suggest an even larger impact of Medicaid on pharmaceutical prices.
} 


\section{The Effect of the Medicaid Market Share on New Drug Introductions}

The model presented in section 3 suggested - if the optimal price for a drug is increasing more rapidly than the Consumer Price Index - then a firm has an incentive to avoid Medicaid's CPI constraint by introducing new versions of its drug at a higher price. Of course, in order to place these new products on the market, the firm must receive approval from the FDA. Approval for a new version of an already approved drug either requires a supplemental new drug application (NDA) or a completely new NDA, depending on the significance of the change. Changes that are expected to have minimal chemical effects - including a different strength of an already approved medication or a change in manufacturing location - can be approved with a supplemental NDA. These do not require any clinical trials and so are relatively inexpensive. Any change in dosage form (e.g. tablet to liquid, extended release) or in the recommended dosage amount will require a new NDA supported by Phase III clinical trials. The manufacturer must show the new form of the drug achieves the same safety and efficacy standards as the original form. The costs of getting approval for a new version of an existing drug are the fee paid to the FDA, the cost of the clinical trials, and the delay. The approximate cost of trials can be measured in the cost per patient recruited into a study, and the number of patients needed to show that the effects, or lack thereof, alleged by the applicant are statistically significant. ${ }^{32}$

Using our Medicaid utilization data, we can determine when new versions of a drug enter the market. For example as described above in the case of Zyprexa, only three versions were released in the drug's first month but seven more were released during the next four years. Of course, even without the CPI constraint the firm may have released new versions of the drug.

\footnotetext{
${ }^{32}$ Average delays for a new NDA are 10 months and for supplemental NDAs are 4-6 months. Fees required by the FDA for either type of application averaged approximately $\$ 500,000$ during our study period. Informal estimates of the costs of clinical trials range from $\$ 500$ to $\$ 10,000$ per patient depending on the length of time required to demonstrate results. For example, a cardiovascular drug would have to be taken longer (several months) than an antibiotic (several days) to demonstrate efficacy.
} 
But in this section we investigate whether drugs that sell differentially to the Medicaid program had more new drug introductions than their counterparts after controlling for other likely determinants of this outcome variable.

\section{A. Are New Versions of Prescription Drugs More Expensive?}

We begin by investigating whether new versions of a drug are indeed more expensive than earlier ones. If they are not, then our hypothesis that Medicaid's CPI constraint creates an important distortion may be less plausible as it would then appear that the profit-maximizing price for the drug was not increasing over time. The example of Zyprexa in Table 1 suggested that the most recent versions of this drug were more expensive even after controlling for dosage amount and in Table 7 we investigate whether this is true more generally by estimating specifications of the following type:

$$
\left.\log _{\left(\text {Price }_{j}\right.}\right)=a+\theta * \text { NotEntrant }_{j}+\mu * \text { YrsSinceEntry }_{j}+\sum_{k=1}^{200} \lambda * I\left(\text { Drug }_{j}=k\right)
$$

In this equation, the unit of observation is the NDC, the outcome variable is the log of the price per prescription, and the variable NotEntrant equals one if an NDC is released after the first year that a drug hits the market and zero otherwise. This specification includes drug fixed effects and therefore estimates the average difference in price between versions of a drug released in the first year that it is available and all later versions of the same drug. We estimate these specifications for NDC's of the top 200 drugs in 1997 and in 2002, with the first sample including 728 observations and the second one including $851 .^{33}$

The statistically significant estimate of .108 for $\theta$ in the first column of Table 7 suggests that newer versions of a drug are approximately 11 percent more expensive than the first version and this result is significant at the ten percent level. We next control with a variable

\footnotetext{
${ }^{33}$ We exclude NDCs for which we do not have an entry date, which is less than $10 \%$ of the sample in both years.
} 
YrsSinceEntry, which is equal to the difference between the year that the NDC entered and the first year that the drug was available. The estimate for this coefficient is negative and statistically insignificant. The results for the analogous specification using the 2002 sample of drugs yield slightly smaller estimates for $\theta$, suggesting a 7-9 percent increase in average price from initial to subsequent versions. Thus this is suggestive evidence of the optimal price for a drug increasing over time.

Given that new versions of a drug may - on average - have different dosage amounts than earlier ones, an alternative and perhaps more appropriate measure of a drug's price is the cost per unit. Thus we next use information in the Medicaid data on total units dispensed in 1997 and in 2002 to calculate this for each NDC. The next two columns summarize the results from specifications using this dependent variable. In these regressions, we interact the drug fixed effects with indicators for route type (e.g. tablet, liquid, ointment, etc.) given that units for the same drug may not otherwise be comparable. Thus the number of fixed effects rises to 287 (from 200) in the 1997 sample and 279 in the 2002 sample. The estimates for $\theta$ in this specification are approximately twice as large, once again suggesting that newer versions of a drug tend to be more expensive.

It is worth noting, however, that the introduction of new versions of existing drugs is not the only explanation for the sharp increases in pharmaceutical prices during the past decade. As previous researchers have noted, new drugs tend to be more expensive than earlier drugs. The results summarized in Table 8 support this finding. Each column summarizes the results from drug-level specifications of the log of average price on measures of years on the market. According to the results summarized in columns (3) and (4) for the 1997 sample, drugs introduced from 1995 to 1997 were almost twice as expensive as those released between 1992 
and 1994. Similarly for the 2002 sample, the drugs entering the market in 2001 and 2002 were substantially more expensive than drugs released between 1998 and 2000. Thus while the results in Table 7 suggest that the optimal price for any given drug may be increasing over time, the optimal price for new treatments appears to be increasing even more rapidly.

\section{B. New Drug Introductions}

In this section we investigate the effect of a drug's Medicaid market share and its sales to the Medicaid program on the number of new NDCs introduced between 1997 and 2002 . We focus on the 1997 sample because we are interested in the entry of new versions of a drug and do not have data beyond 2002 to examine subsequent entry for our more recent sample. In addition to the explanatory variables used in the pricing regressions in Tables 5 and 6 , we control for two additional variables that are likely to influence the rate at which new versions of a drug are introduced. The first $\log (\operatorname{Sales} 97)$, is simply equal to the log of total U.S. revenues for the drug in 1997. Because of the fixed costs of new version, as the total revenues for a drug increase the potential gains to releasing new versions will as well. In some specifications we also control for the number of NDCs in 1997 (NumNDC), as this may capture underlying demand and costs for different versions of a drug. But given that the Medicaid share may have influenced this variable as well we estimate specifications both with and without it of the following type:

$$
\begin{aligned}
& \text { NewNDC }_{\mathrm{j}, 97-02}=\phi_{0}+\phi_{1} \text { MMS }_{\mathrm{j}, 97}+\phi_{2} \text { GenComp }_{\mathrm{j}, 97}+\phi_{3} \text { Subst }_{\mathrm{j}, 97}+\phi_{4} \text { Years }_{\mathrm{j}, 97} \\
& \left.+\phi_{5} \log \left(\operatorname{Sales}_{\mathrm{j}, 97}\right)+\phi_{6} \text { NumNDC }_{\mathrm{j}, 97}+\phi_{8} \operatorname{GenComp}_{\mathrm{j}, 02}+\sum_{\mathrm{k}=1}^{14} \theta_{\mathrm{k}} * \mathrm{I} \text { Class }_{\mathrm{j}, 97}=\mathrm{k}\right)
\end{aligned}
$$

In this regression, the variable $N e w N D C$ is simply equal to the number of NDCs with more than $0.1 \%$ of a drug's sales in 2002 and that had no utilization in 1997. We run Poisson regressions in this case given that the values for this variable are all integers and range from 0 to 6 . 
The first two columns of Table 9 summarize the results from specifications using all 200 drugs from the 1997 sample. In both cases, the estimate for the $\log$ (Sales) coefficient is significantly positive while the coefficient estimate for Years on the market is significantly negative. As predicted, the estimate for the Medicaid share is positive though it is not statistically significant. However in the subsequent two columns we focus on those drugs in our sample that did not face generic competition in 1997. Drugs with generic competition will gain less from introducing new versions of the brand as they face declining sales. For drugs with no such competition, the Medicaid share is significantly positively related with the number of new NDCs introduced.

In the next four columns we list the results from analogous specifications that include three indicator variables (50-99 million, 100-199 million, and 200+ million) for total sales to Medicaid. Holding fixed a drug's total revenues, as it sells more to Medicaid the optimal rate of new drug introduction should increase. These results yield a similar picture, suggesting that firms producing drugs with very high Medicaid sales are significantly more likely to introduce new versions than observably similar drugs with low sales to the program. For example, the positive and significant point estimate of 1.113 for Medicaid Sales $>200$ million in specification (8) suggests that the rate of new drug introduction for drugs with more than 200 million in Medicaid sales is $205 \%$ higher than for those with less than 50 million in Medicaid sales. Similarly firms producing drugs with Medicaid sales between 100 and 200 million introduce new versions at a $145 \%$ higher rate than firms selling drugs with low Medicaid sales and this effect is significant at the ten percent level. This final set of results therefore suggests that firms to some extent get around the Medicaid CPI constraint - which aims to restrain the growth rate of pharmaceutical spending - by introducing new and more expensive versions of their drugs. 


\section{Discussion}

The first set of results summarized in this paper demonstrate that prescription drugs sold differentially to low-income Medicaid recipients have significantly higher prices than do otherwise similar drugs. Because the Medicaid price is based on prices paid in the U.S. private sector, firms have a strong incentive to charge private patients more for their drugs than they otherwise would. To the extent this happens, some private patients who would otherwise purchase these drugs are priced out of the market. Our second set of findings, that Medicaid's

CPI constraint creates additional product proliferation beyond what would exist in the absence of this constraint, is somewhat more subtle. The regulation only limits price increases for existing products, so a firm can introduce a new product to obtain freedom to raise prices. Because of the fixed cost of introducing a new version, this strategy is only attractive for drugs with large sales to Medicaid and drugs expected to continue to have large sales to Medicaid. Our evidence indicates that the manufacturers of these drugs find the benefit of a new version outweighs the fixed cost required; our data show that these drugs proliferate more new NDCs than would otherwise be expected during our study period.

The combination of these two findings leads us to conclude that the Medicaid procurement regulations distort market outcomes. Government involvement in the private market - simply through the government's own pricing rules - causes change in the equilibrium prices faced by private consumers. We suspect our findings capture the unintended consequences of policy made with good intentions. Policy makers might be averse to setting an absolute price for procurement because it is difficult to get that right and price has both important distributional 
consequences and substantial effects on innovation incentives. So linking the government price to the private sector price seems like a good idea.

But an important cost of doing this is the effect on private sector prices. Medicaid's price-setting rules may substantially lower allocative efficiency for certain drug treatments, as some low valuation Medicaid recipients take the drug while other high-valuation consumers without Medicaid coverage do not. Even without this efficiency effect, non-Medicaid consumers may purchase health insurance or try to become eligible for Medicaid to reduce their medical expenditure, thus leading to further increases in prices.

We conjecture that our findings may partially explain why certain drugs are so expensive. For examples drugs used to treat antipsychotic illness and HIV/AIDS - the two most expensive categories of drug according to a recent report (NIHCM, 2002) - are differentially used by Medicaid recipients, with market shares of approximately $75 \%$ and $45 \%$, respectively. ${ }^{34}$

Measured Medicaid market share is likely to be an underestimate of the influence of the Medicaid procurement rules because there are additional public health programs that are entitled to purchase pharmaceutical products at Medicaid prices. The 340B program of the Veterans Healthcare Act of 1992 (VHCA) allows some public health service programs to effectively join the Medicaid procurement program. ${ }^{35}$ For example, the Veterans Administration and state ADAP programs (AIDS drug assistance programs), along with others, may get their drugs this way. Thus likely our $18.5 \%$ Medicaid market share is lower than the total share of the market that is sold under the Medicaid regulations. We do not have the data to measure drug-specific expenditures by these other programs. As long as they are not both large and disproportionately

\footnotetext{
${ }^{34}$ The market share for HIV/AIDS drugs increases to almost $65 \%$ if one includes ADAP expenditures, which use Medicaid prices.

${ }^{35}$ Aldridge and Doyle (2002)
} 
purchasing non-Medicaid drugs, then Medicaid share remains a good proxy for the size of purchases under Medicaid rules.

Our results take on additional policy significance when one considers that government involvement in this sector will soon expand by a great deal due to the new Medicare prescription drug benefit. As the proportion of insured patients increases and inelastic government purchases make up an even greater share of the market, there is cause for concern that prices may rise substantially, to some extent offsetting the benefit to Medicare recipients and harming other health care consumers as well.

Many have argued that U.S. pays too much for prescription drugs; this feedback from public to private may partially explain why pharmaceutical prices in the US are relatively high. While any method of procurement has its problems, in our view, up to this point policy makers have not focused sufficient attention on the effect that linking public and private markets has on the prices paid by consumers in the private sector. Whether our results generalize to other categories of health care or to other types of government procurement represent important topics for future research. 


\section{References:}

Aldridge, Chris and Arnold Doyle (2002) "AIDS Drug Assistance Programs - Getting the Best Price? Issue Brief National ADAP Monitoring Project, April 2002.

Averch, Harvey and Leland Johnson (1962) "Behavior of the Firm Under Regulatory Constraint" American Economic Review: 52:5:1052-1069.

Borrell, J.R. (1999) "Pharmaceutical Price Regulation - A study on the impact of the rate-ofreturn regulation in the UK" PharmacoEconomics:15:3:291-303.

Currie, Janet and Jeffrey Grogger (2002) "Medicaid Expansions and Welfare Contractions: Offsetting Effects on Prenatal Care and Infant Health?" Journal of Health Economics 21: 313-335.

Cutler, David, and Jonathan Gruber (1996) "Does Public Insurance Crowd Out Private Insurance?” Quarterly Journal of Economics 111, 391-430.

Duggan, Mark (2004) "Do new prescription drugs pay for themselves? The case of secondgeneration anti-psychotics" forthcoming in the Journal of Health Economics.

Epstein, Arnold and Joseph Newhouse (1998) “The Impact of Medicaid Expansions on Early Prenatal Care and Health Outcomes," Health Care Financing Review 19(4), 85-99.

Frank, Richard G, Salkever, David S. (1997) "Generic Entry and the Pricing of Pharmaceuticals" Journal of Economics and Management Strategy : 6:1:75-90, Spring 1997.

Frank, Richard G., Salkever, David S. (1992) "Pricing, Patent Loss and the Market for Pharmaceuticals” Southern Economic Journal:59:2:165-179, October 1992.

Gruber, Jonathan and AaronYelowitz (1999) "Public Health Insurance and Private Saving," Journal of Political Economy 107(6), 1249-1274.

Gruber, Jonathan (2003) "Medicaid" in Means-Tested Transfer Programs in the United States. Edited by Robert Moffitt, NBER, Cambridge.

Holmstrom, Bengt and Paul Milgrom (1991) "Multitask Principal-Agent Analyses: Incentive Contracts, Asset Ownership, and Job Design" Journal of Law, Economics, \& Organization, Vol. 7, Special Issue: [Papers from the Conference on the New Science of Organization, January 1991], pp. 24-52.

Ikegami, Naoki, Shunya Ikeda, and Hiroki Kawai (1998) "Why medical care costs in Japan have increased despite declining prices for pharmaceuticals" Pharmoeconomics:14:97-105 Suppl. 1. 
Kaiser Commission on Medicaid and the Uninsured (2001) "Medicaid Outpatient Prescription Drug Benefits: Findings from a National Survey and Selected Case Study Highlights."

Martinez, Barbara (2004) "Drug-Price Surge May Erode Savings from Medicare Card" Wall Street Journal March 24, 2004 page B1.

National Health Policy Forum (2002), “Average Wholesale Prices for Prescription Drugs: Is There a More Appropriate pricing Mechanism?” NHPF Issue Brief \# 775.

National Institute for Health Care Management (2002) "Prescription Drug Expenditures in 2001: Another Year of Escalating Costs.”

Newhouse, Joseph (2004) "How much should Medicare pay for prescription drugs?" Health Affairs: 23(1) 89-102.

Olson, Mary (1996) "Substitution in regulatory agencies: FDA enforcement alternatives" Journal of Law, Economics and Organization:12:2:376-407.

Parker, D. (1999) "The performance of BAA before and after privatization - A DEA study" Journal of Transport Economics and Policy: 33:133-145 part 2.

Scott Morton, Fiona (1997) "The strategic response to pharmaceutical firms to the Medicaid most-favored-customer rules" RAND Journal of Economics:28:2:269-290.

Yelowitz, Aaron (1995) "The Medicaid Notch, Labor Supply, and Welfare Participation: Evidence from Eligibility Expansions.” Quarterly Journal of Economics 105: 909-940. 
Table 1: Medicaid Utilization for Zyprexa in 2002

\begin{tabular}{|c|c|c|c|c|c|c|}
\hline Dosage & Spending & \# Scripts & Avg Paid & FDA & Enter & Route Type \\
\hline $10 \mathrm{MG}$ & 637.1 & 1722.1 & $\$ 370$ & $9 / 96$ & $9 / 96$ & Regular Tablet \\
\hline $5 \mathrm{MG}$ & 300.4 & 1449.0 & $\$ 207$ & $9 / 96$ & $9 / 96$ & Regular Tablet \\
\hline $15 \mathrm{MG}$ & 225.9 & 528.7 & $\$ 427$ & $9 / 97$ & $1 / 00$ & Regular Tablet \\
\hline $20 \mathrm{MG}$ & 191.5 & 371.7 & $\$ 515$ & $9 / 97$ & $12 / 00$ & Regular Tablet \\
\hline $2.5 \mathrm{MG}$ & 177.6 & 1077.9 & $\$ 165$ & $5 / 97$ & $5 / 97$ & Regular Tablet \\
\hline $7.5 \mathrm{MG}$ & 76.9 & 338.1 & $\$ 228$ & $9 / 96$ & $9 / 96$ & Regular Tablet \\
\hline $10 \mathrm{MG}$ & 24.4 & 70.0 & $\$ 391$ & $4 / 00$ & $8 / 00$ & Dissolvable Tablet \\
\hline $5 \mathrm{MG}$ & 19.3 & 82.4 & $\$ 234$ & $4 / 00$ & $8 / 00$ & Dissolvable Tablet \\
\hline $20 \mathrm{MG}$ & 7.1 & 12.9 & $\$ 548$ & $4 / 00$ & $9 / 01$ & Dissolvable Tablet \\
\hline $15 \mathrm{MG}$ & 5.5 & 11.9 & $\$ 459$ & $4 / 00$ & $9 / 01$ & Dissolvable Tablet \\
\hline All & 1668.5 & 5664.7 & $\$ 295$ & $9 / 96$ & $9 / 96$ & All \\
\hline
\end{tabular}

Table 2: Summary Statistics for 1997 Sample of Top 200 Drugs

\begin{tabular}{|c|c|c|c|c|}
\hline Variable & Mean & Std. Dev. & Min. & Max. \\
\hline Total Revenues (/ 1000) & 255756 & 307930 & 53708 & 2188413 \\
\hline Medicaid Revenues (/ 1000) & 43274 & 65161 & 3 & 413699 \\
\hline Medicaid Share & .165 & .151 & .00 & 1.00 \\
\hline Price per Prescription & 141 & 223 & 18 & 1645 \\
\hline Log (Price per Prescription) & 4.39 & 0.90 & 2.87 & 7.41 \\
\hline Price Rank & 100.5 & 57.9 & 1 & 200 \\
\hline Number of NDCs in 1997 & 3.73 & 2.52 & 1 & 15 \\
\hline Number of NDCs in 2002 & 4.12 & 2.63 & 1 & 17 \\
\hline Number of new NDCs & 0.58 & 1.03 & 0 & 6 \\
\hline \# of Competitors & 6.27 & 3.56 & 0 & 24 \\
\hline Any Generic Competition & .280 & .450 & 0 & 1 \\
\hline Years on Market & 9.10 & 8.30 & 0 & 55 \\
\hline
\end{tabular}


Table 3: Summary Statistics for 2002 Sample of Top 200 Drugs

\begin{tabular}{|c|c|c|c|c|}
\hline Variable & Mean & Std. Dev. & Min. & Max. \\
\hline Total Revenues (/ 1000) & 583024 & 718636 & 117039 & 5677668 \\
\hline Medicaid Revenues (/ 1000) & 102186 & 172950 & 108 & 1668500 \\
\hline Medicaid Share & .177 & .150 & .00 & 1.00 \\
\hline Price per Prescription & 280 & 449 & 20 & 2883 \\
\hline Log (Price per Prescription) & 4.90 & 1.09 & 3.01 & 7.97 \\
\hline Price Rank & 100.5 & 57.9 & 1 & 200 \\
\hline \# of Competitors & 6.26 & 3.27 & 0 & 15 \\
\hline Any Generic Competition & .165 & .372 & 0 & 1 \\
\hline Years on Market & 8.23 & 7.48 & 0 & 60 \\
\hline
\end{tabular}

Table 4: Summary Statistics for Price and Log(Price) in 1997 and 2002 Samples

\begin{tabular}{|c|c|c|c|c|}
\hline & 1997 Price & $1997 \log ($ Price $)$ & 2002 Price & $2002 \log ($ Price $)$ \\
\hline Mean & 140.94 & 4.389 & 280.23 & 4.897 \\
\hline $5 \%$ & 30.42 & 3.415 & 39.63 & 3.680 \\
\hline $10 \%$ & 34.48 & 3.540 & 47.03 & 3.851 \\
\hline $25 \%$ & 43.04 & 3.762 & 60.81 & 4.108 \\
\hline $50 \%$ & 62.65 & 4.138 & 92.69 & 4.529 \\
\hline $75 \%$ & 107.94 & 4.681 & 232.45 & 5.445 \\
\hline $90 \%$ & 415.19 & 6.028 & 878.58 & 6.778 \\
\hline $95 \%$ & 555.82 & 6.320 & 1190.17 & 7.082 \\
\hline
\end{tabular}




\section{Table 5: The Impact of Medicaid Market Share on Pharmaceutical Prices in 1997}

(1)

\author{
Medicaid Market Share in 1997 \\ Any Generic Competition in 1997 \\ \# of Therapeutic Substitutes in 1997
}

Years on Market in 1997

Number Observations

Therapeutic Class Fixed Effects?

$$
\text { R-squared }
$$

Log(Price per Prescription)

(2)

(3)

(4)

$0.716^{* *}$

$0.742^{* \star *}$

(.322)

$0.804^{* *}$

(.317)

$-0.335^{* * *}$

$-0.349^{* * *}$

(.097)

$-0.018$

(.015)

0.746 **

(.095)

$-0.236^{\star \star}$

$-0.019$

$-0.019^{\star \star *}$

(.006)

$\begin{array}{cccc}200 & 200 & 200 & 200 \\ \text { Yes } & \text { Yes } & \text { Yes } & \text { Yes } \\ 0.534 & 0.558 & 0.565 & 0.587\end{array}$

Specifications include the top 200 drugs (excluding over-the-counter and generic) in 1997 based on total sales from IMS. The dependent variable in specifications one through four is the log of the average price per prescription. Each specification includes 14 therapeutic class fixed effects. Huber-White standard errors are reported in parentheses.

(5)

$44.9^{* *}$

Any Generic Competition in 1997

\# of Therapeutic Substitutes in 1997

Years on Market in 1997

Number Observations

Therapeutic Class Fixed Effects?

$$
\text { R-squared }
$$

\section{Price Rank}

(6)

(7)

(8)

$\begin{array}{ccc}46.5^{* * *} & 53.2^{* * *} & 49.6^{* * *} \\ (17.9) & (18.1) & (17.8) \\ -20.0^{* * *} & -21.4^{* * *} & -14.5^{* *} \\ (7.0) & (7.0) & (6.7) \\ & -2.0^{*} & -2.0^{*} \\ & (1.0) & (1.0) \\ & & -1.2^{* * *} \\ & & (0.4) \\ 200 & 200 & 200 \\ \text { Yes } & \text { Yes } & \text { Yes } \\ 0.520 & 0.531 & 0.554\end{array}$

Specifications include the top 200 drugs (excluding over-the-counter and generic) in 1997 based on total sales from IMS. The dependent variable in specifications one through four is the price rank for each drug (200 is most and 1 is least expensive). Each specification includes 14 therapeutic class fixed effects. Huber-White standard errors are reported in parentheses.

\footnotetext{
${ }^{* * *},{ }^{* *}$, and ${ }^{*}$ represent significance at the one, five, and ten percent levels, respectively.
} 


\section{Table 6: The Impact of Medicaid Market Share on Pharmaceutical Prices in 2002}

Medicaid Market Share in 2002

Any Generic Competition in 2002

\# of Therapeutic Substitutes in 2002

Years on Market in 2002

Number Observations

Therapeutic Class Fixed Effects?

$$
\text { R-squared }
$$

(1)

Log(Price per Precription)

(3)

$0.939^{* *}$

$0.969^{* *}$

(.432)

$-0.328^{* *}$

$.966^{* *}$

(.430)

$-0.328^{* *}$

(.138)
0.001

(.020)

$\begin{array}{ccc} & & -.026^{\star * *} \\ & & (.009) \\ 200 & 200 & 200 \\ \text { Yes } & \text { Yes } & \text { Yes } \\ 0.592 & 0.592 & 0.600\end{array}$

Specifications include the top 200 drugs (excluding over-the-counter and generic) in 2002 based on total sales from IMS. The dependent variable in specifications one through four is the log of the average price per prescription. Each specification includes 14 therapeutic class fixed effects. Huber-White standard errors are reported in parentheses.

(5)

$65.2^{* * *}$

Any Generic Competition in 2002

\# of Therapeutic Substitutes in 2002

Years on Market in 2002
(6)

$67.3^{* * *}$

$-21.9^{* *}$

Price Rank

(7)

$67.9^{* * *}$

(20.1)

$-21.9^{* *}$

(8.5)

$-0.3$

(8)

$69.7^{* * *}$

$-0.6$

Number Observations

200
Yes
0.517

200

Yes

0.535

200

Yes

200

Yes

0.557

Specifications include the top 200 drugs (excluding over-the-counter and generic) in 2002 based on total sales from IMS. The dependent variable in specifications one through four is the price rank for each drug (200 is most and 1 is least expensive). Each specification includes 14 therapeutic class fixed effects. Huber-White standard errors are reported in parentheses. 
Table 7: Are New Versions of the Same Drug More Expensive?

1997 Drugs

Later Version

Years After Entry

\# Observations

R-squared

Drug Fixed Effects?

Drug-Route Fixed Effects?
Log(Price per Prescription)

(1)

$0.108^{*}$

(.057)

728
0.782
Yes
No

(2)

0.083

(.074)

$-0.005$

(.011)

728
0.782
Yes
No

Log(Price per Unit)

(3)

$0.191^{* * *}$

(.072)

$0.248^{* *}$

0.012

(.012)

728

728

0.907

0.907

Yes

Yes
Yes

Yes

Specifications include NDCs for the top 200 drugs (excluding over-the-counter and generic) in 1997 based on total sales from IMS. The dependent variable in specifications one and two is the log of the average price per prescription while in three and four it is the log of the average price per unit. The first two specifications include 200 drug fixed effects while the last two include 287 drug-route fixed effects. Huber-White standard errors are reported in parentheses.

\begin{tabular}{lcccc} 
2002 Drugs & \multicolumn{2}{c}{ Log(Price per Script) } & \multicolumn{2}{c}{ Log(Price per Unit) } \\
& $(5)$ & $(6)$ & $(7)$ & $(8)$ \\
Later Version & 0.071 & 0.091 & $0.203^{* * *}$ & 0.093 \\
& $(.057)$ & $(.066)$ & $(.064)$ & $(.082)$ \\
Years After Entry & & -0.004 & & $0.021^{*}$ \\
& & $(.008)$ & & $(.012)$ \\
\# Observations & 851 & 851 & 851 & 851 \\
R-squared & 0.865 & 0.865 & 0.942 & 0.942 \\
Drug Fixed Effects? & Yes & Yes & Yes & Yes \\
Drug-Route Fixed Effects? & No & No & Yes & Yes \\
& & & & \\
& & &
\end{tabular}




\section{Table 8: Are More Recent Drugs More Expensive?}

\begin{tabular}{|c|c|c|c|c|c|c|c|c|}
\hline & \multicolumn{8}{|c|}{ Log(Price per Prescription) } \\
\hline & & 1997 & ample & & & 2002 & ample & \\
\hline & (1) & (2) & (3) & (4) & (5) & (6) & (7) & (8) \\
\hline Years since Entry & $\begin{array}{c}-0.035^{* * *} \\
(.006)\end{array}$ & $\begin{array}{c}-0.024^{* * *} \\
(.007)\end{array}$ & & & $\begin{array}{c}-0.064^{* * *} \\
(.013)\end{array}$ & $\begin{array}{c}-0.039^{* * *} \\
(.010)\end{array}$ & & \\
\hline Entered 1992-1994 & & & $\begin{array}{l}0.088 \\
(.136)\end{array}$ & $\begin{array}{l}0.100 \\
(.095)\end{array}$ & & & $\begin{array}{l}0.189 \\
(.216)\end{array}$ & $\begin{array}{l}0.135 \\
(.145)\end{array}$ \\
\hline Entered 1995-1997 & & & $\begin{array}{c}0.732^{* * *} \\
(.249)\end{array}$ & $\begin{array}{c}0.615^{* * *} \\
(.197)\end{array}$ & & & $\begin{array}{c}0.419^{* *} \\
(.183)\end{array}$ & $\begin{array}{l}0.174 \\
(.126)\end{array}$ \\
\hline Entered 1998-2000 & & & & & & & $\begin{array}{c}0.729^{* * *} \\
(.213)\end{array}$ & $\begin{array}{c}0.459^{* * *} \\
(.160)\end{array}$ \\
\hline Entered 2001-2002 & & & & & & & $\begin{array}{c}1.445^{\star * *} \\
(.374)\end{array}$ & $\begin{array}{c}0.892^{* * *} \\
(.246)\end{array}$ \\
\hline \# Observations & 200 & 200 & 200 & 200 & 200 & 200 & 200 & 200 \\
\hline R-squared & 0.102 & 0.564 & 0.067 & 0.567 & 0.097 & 0.616 & 0.127 & 0.626 \\
\hline Class Fixed Effects? & No & Yes & No & Yes & No & Yes & No & Yes \\
\hline
\end{tabular}

Specifications one through four include the top 200 drugs (excluding over-the-counter and generic) in 1997 while five through eight include the top 200 from 2002 based on total sales from IMS. The dependent variable in each specification is the log of the average price per prescription. The odd-numbered specifications include therapeutic class fixed effects. Huber-White standard errors are reported in parentheses. 


\section{Table 9: Poisson Maximum Likelihood Estimates of Impact of Medicaid Sales on NDC Introductions}

Medicaid Share in 1997

Medicaid Sales 50-99 million

Medicaid Sales 100-199 million

Medicaid Sales 200 million+

$\log ($ Sales97)

Any Generic Competition in 97

\# of Ther. Substitutes in 97

Years on Market in 97

Any Generic Competition in 02

Number of NDC's in 97

Number Observations

Ther. Class Fixed Effects?
(1)

(2)

\subsection{4}

(.777)
\# of New NDCs 98-02

(3)

(4)

(5)

(6)

(7)
0.618
$1.353^{* *}$
$1.309^{*}$
(.745)
(.651)
(.676)

\begin{tabular}{|c|c|c|c|c|c|c|c|c|}
\hline Log(Sales97) & $\begin{array}{c}0.591^{* * *} \\
(.119)\end{array}$ & $\begin{array}{c}0.504^{* * *} \\
(.121)\end{array}$ & $\begin{array}{c}0.629^{* * *} \\
(.139)\end{array}$ & $\begin{array}{c}0.564^{* * *} \\
(.139)\end{array}$ & $\begin{array}{c}0.546^{* * *} \\
(.175)\end{array}$ & $\begin{array}{c}0.374^{* *} \\
(.171)\end{array}$ & $\begin{array}{c}0.486^{* *} \\
(.195)\end{array}$ & $\begin{array}{l}0.308^{*} \\
(.184)\end{array}$ \\
\hline Any Generic Competition in 97 & $\begin{array}{l}0.058 \\
(.313)\end{array}$ & $\begin{array}{l}-0.034 \\
(.363)\end{array}$ & & & $\begin{array}{l}0.044 \\
(.310)\end{array}$ & $\begin{array}{l}-0.076 \\
(.376)\end{array}$ & & \\
\hline \# of Ther. Substitutes in 97 & $\begin{array}{l}-0.037 \\
(.035)\end{array}$ & $\begin{array}{l}-0.031 \\
(.036)\end{array}$ & $\begin{array}{l}-0.054 \\
(.043)\end{array}$ & $\begin{array}{l}-0.032 \\
(.044)\end{array}$ & $\begin{array}{l}-0.035 \\
(.034)\end{array}$ & $\begin{array}{l}-0.033 \\
(.036)\end{array}$ & $\begin{array}{l}-0.047 \\
(.040)\end{array}$ & $\begin{array}{l}-0.032 \\
(.042)\end{array}$ \\
\hline Years on Market in 97 & $\begin{array}{l}-0.039 \\
(.023)\end{array}$ & $\begin{array}{c}-0.071^{* * *} \\
(.030)\end{array}$ & $\begin{array}{c}-0.048^{* *} \\
(.023)\end{array}$ & $\begin{array}{c}-0.088^{* * *} \\
(.025)\end{array}$ & $\begin{array}{l}-0.041 \\
(.024)\end{array}$ & $\begin{array}{l}-0.074 \\
(.032)\end{array}$ & $\begin{array}{c}-0.052^{* *} \\
(.024)\end{array}$ & $\begin{array}{c}-0.102^{* * *} \\
(.028)\end{array}$ \\
\hline Any Generic Competition in 02 & & $\begin{array}{l}0.122 \\
(.279)\end{array}$ & & $\begin{array}{l}0.101 \\
(.328)\end{array}$ & & $\begin{array}{l}0.105 \\
(.282)\end{array}$ & & $\begin{array}{l}0.089 \\
(.342)\end{array}$ \\
\hline Number of NDC's in 97 & & $\begin{array}{c}0.134^{* * *} \\
(.039)\end{array}$ & & $\begin{array}{c}0.165^{\star * *} \\
(.035)\end{array}$ & & $\begin{array}{c}0.141^{* * *} \\
(.041)\end{array}$ & & $\begin{array}{c}0.197^{* * *} \\
(.036)\end{array}$ \\
\hline Number Observations & 200 & 200 & 144 & 144 & 200 & 200 & 144 & 144 \\
\hline Ther. Class Fixed Effects? & Yes & Yes & Yes & Yes & Yes & Yes & Yes & Yes \\
\hline
\end{tabular}

Specifications include the top 200 drugs (excluding over-the-counter and generic) in 1997 based on total sales from IMS. The dependent variable in each specification is the number of NDCs entering between 1997 and 2002 for each drug. Each specification includes 14 therapeutic class fixed effects. Huber-White standard errors are reported in parentheses 